\title{
Delayed Treatment of Secondary Iris Cyst due to Blunt Ocular Trauma
}

\author{
Tjahjono D Gondhowiarjo, Widya Artini
}

Department of Ophthalmology, Faculty of Medicine Universitas Indonesia, Cipto Mangunkusumo Hospital, Jakarta, Indonesia.

\section{Corresponding Author: \\ Dr. Widya Artini}

Email: ikkesumantri@gmail.com

This is an Open Access article distributed under the terms of the Creative Commons Attribution License (creativecommons.org/ licenses/by/3.0).

Received : September 25, 2017

Accepted : December 8, 2017

Published : January 20, 2018

\begin{abstract}
Background: Epithelial iris cysts are derived due to genetic factors or caused by ocular trauma. Case Report: We report the case of a five-year-old boy with blurred vision after a rubber bullet toy hit his left eye. There was a wide iris cyst of more than $180^{\circ}$ in extent, attached to the corneal endothelium on the nasal side, with a still clear cornea. His vision in affected eye reduced to hand movement with intraocular pressure of $40 \mathrm{mmHg}$. The whole cornea was edematous and the iris cyst had grown significantly in terms of size. We performed a successful iris cyst removal followed by Ahmed drainage implant that resulted in moderate visual improvement. Conclusion: Iris cyst can develop secondary to neglected ocular trauma.
\end{abstract}

Keywords: Corneal Endothelium, Cysts, Drainage, Eye Injuries, Intraocular Pressure, Iris Diseases.

\section{Introduction}

Epithelial iris cysts are derived from iris epithelium developed in the anterior chamber. Primary epithelial cysts can be caused by genetic factors in people of certain racial background, while most cases of secondary epithelial cysts are caused by ocular trauma $[1,2]$. The most common form of secondary iris cyst is a peripheral iris pigment epithelial cyst (55\%) [3].

\section{Delayed treatment may cause} decompensation of the corneal endothelium due to attachment of the cyst which has grown into the anterior chamber. The iris cyst develops either from a break in the epithelium or iris stroma; aqueous humor then enters through this port de entrée and creates a space in between where the cyst will grow, eventually reaching the corneal endothelium and resulting in corneal edema [2-5]. Various surgical procedures for iris cysts have been reported and the result depends on the size of the cyst, the affected area of camera oculi anterior and prompt treatment [6-9].
The aim of our case report is to demonstrate the natural development of an iris cyst due to a neglected blunt trauma resulting in delayed treatment; noticing that treatment would be less complicated if done in the first admission.

\section{Case Report}

A 5-year-old boy came to our outpatient eye clinic with complaints of blurred vision and a painful left eye. His eye was hit by a rubber bullet from a toy gun four days back. The examination performed by a pediatric ophthalmologist revealed the following results: the visual acuity of his right eye was $6 / 7.5$ and of his left eye was 6/30 with correction; while the intraocular pressure (IOP) of his right eye was $15 \mathrm{mmHg}$ and the pressure of his left eye was 30 $\mathrm{mmHg}$.

The patient was then referred to a refractive eye surgeon and glaucoma specialist. The examination during his initial visit revealed the following results: the visual acuity of his right eye was $6 / 7.5$ and $6 / 30$ on his left eye, which could not 
be corrected; the IOP of the right eye was $12 \mathrm{mmHg}$ and of the left eye was $35 \mathrm{mmHg}$ (Icare $\AA$ tonometer TA01i, USA). The results of slit-lamp examination on his right eye were within normal limits, for both anterior and posterior segments. The left eye showed a hyperemic conjunctiva, a clear cornea but there was an iris cyst on the nasal side covering an area of less than $180^{\circ}$. The epithelial pigment layer of iris was attached to the cornea endothelium; however the adjacent tissue of the cornea was still clear [Fig.1a]. Over the superior, temporal and inferior quadrants, the anterior chamber angle was open. The fundus photograph revealed that the retina was normal and optic disk was in a good condition with a cup/disc ratio of 0.3 . There was no nasalization of vessels or optic disc cupping. Anterior chamber ocular coherence tomography (AC-OCT) was performed and confirmed an iris cyst on the nasal side with iris epithelium attached to the corneal endothelium and across to the lens surface at the base of the iris cyst. This imaging showed adequate iris cyst visualization and clear iris cyst space [Fig.2]. Based on the results of these examinations, the patient was diagnosed with having secondary iris cyst due to blunt trauma, and ocular hypertension. The differential diagnosis was primary iris cyst, iris cyst tumor, pigmented iris epithelium. We planned to do iris cyst removal, but the patient was lost to follow-up. Patient came two weeks later, and was found to have a growing iris cyst up to the corneal endothelium, leading to an edematous cornea as seen on nasal view [Fig.1b], with visual acuity of 3/60 and IOP of $40 \mathrm{mmHg}$. We treated the child with timolol $0.5 \%$, brinzolamide and brimonidine eye drops and planned to do iris cyst removal. Unfortunately, the patient refused surgical treatment, even though we had informed his parents of consequences.

The patient came again two months later with a complaint of greater pain in his left eye. The iris cyst had developed progressively and there was edema around the cornea [Fig.3]. The visual acuity of the left eye was hand movement and IOP was
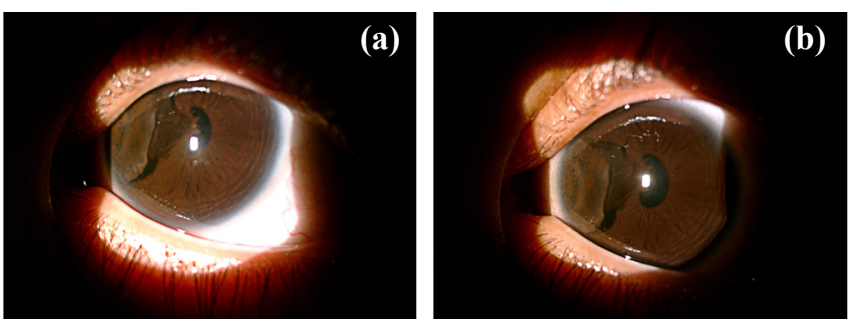

Fig.1: (a): The surface of the iris is attached to the corneal endothelium (nasal side); (b): the attachment of iris is seen more obvious in another two weeks.

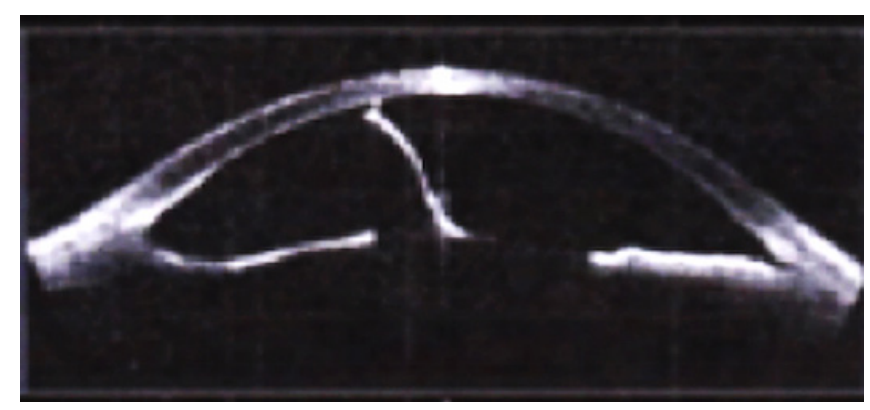

Fig.2: Results of anterior segment OCT showing the iris epithelial cyst; the iris cyst is touching the corneal endothelium. The base of iris is attached to the surface of the lens.

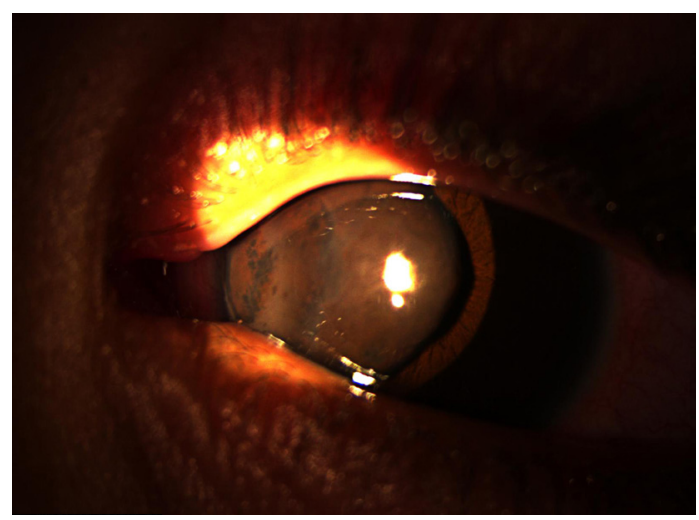

Fig.3: Slit lamp examination of left eye after two months showed that the whole cornea is edematous with a high IOP.

high (palpation). The iris cyst removal surgery was done as an en-block technique by separating the surface of the cyst from the corneal endothelium and from the lens surface using viscoelastic through a second port. The iris cyst was removed slowly through corneal-limbal incision at the nasal side. After the cyst was outside the anterior 
chamber, peripheral iris cyst was cut with resultant around pupil. At the end of surgery, the anterior chamber was reformed and corneal-limbal incision closed with 10-0 nylon. Following surgery, the conjunctiva was hyperemic and cornea edematous on nasal side. Two months after surgery, visual acuity improved to $5 / 60$ with clear cornea over central area, and cicatrix on nasal part of cornea [Fig.4]. IOP was reduced to $25 \mathrm{mmHg}$ with fixedcombination of timolol and prostaglandin analog. Ahmed drainage implant surgery (New World Medical) was then performed under general anesthesia. After 4 months follow up, visual acuity remained at 5/60 with IOP $16 \mathrm{mmHg}$ and corneal decompensation on the nasal side. We plan to perform posterior lamellar keratoplasty surgery or descemet-stripping endothelial keratoplasty (DSEK) to relieve the corneal edema.

\section{Discussion}

Iris epithelial cysts are very rare, especially secondary iris cysts. Moreover, with advances in diagnostic technology and excellent surgical techniques, secondary iris cysts have become even more uncommon [10]. We report a rare case of secondary iris epithelial cyst following blunt trauma. We have explained that the cyst has developed quite progressively, which began with the occurrence small iris cyst at first admission then aggressively growing with resultant corneal edema leading to drastically reduced visual acuity. Delayed treatment and limited knowledge of the patient's condition in the patient's family are one of the reasons for this situation.

The irregular curvature of iris cyst and thin wall has led to the diagnosis of an iris epithelial cyst [11]. It has been shown that the results of imaging with AS-OCT examination are as good as the results of ultrasound biomicroscopy (UBM) examination [12]. However, in the case that has involved the anterior structure of the eye, UBM examination can provide a more visible feature of the cyst such as the cyst wall and the adjacent tissues [13].

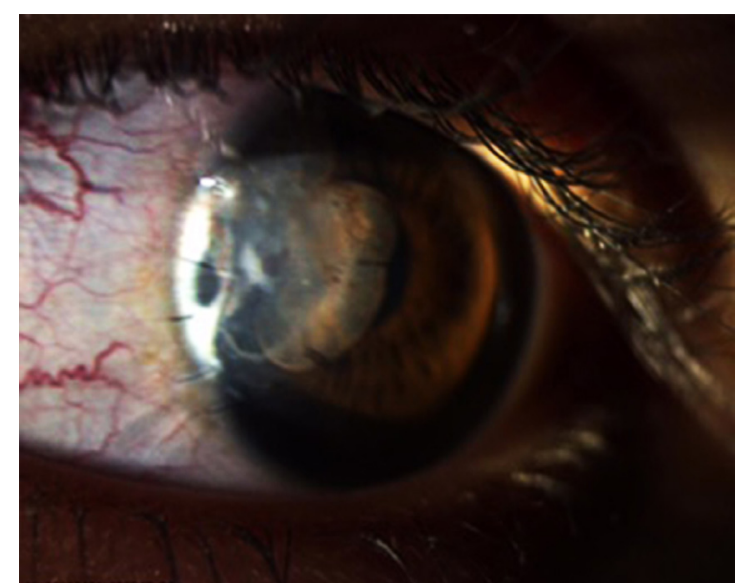

Fig.4: Results after the iris removal surgery.

On the AS-OCT examination, our patient showed an unrounded cyst and its correlation to the adjacent eye tissue. We also did not perform cyst aspiration because the cyst was so large that it almost covered the anterior segment. En-bloc excision cyst surgery under general anesthesia was performed, however further treatment such as cyrotherapy, endo-photocoagulation or endodiathermy was not performed [14]. Nonetheless, the procedure that has been performed by us has also been reported by other reports showing satisfactory results $[15,16]$. Further treatment such as glaucoma implant surgery is essential to overcome secondary ocular hypertension. Further evaluation for glaucoma diagnosis and cornea decompensation is needed. DSEK surgery may be necessary to retreat cornea endothelial decompensation.

\section{Conclusion}

We report a case of a rapidly growing epithelial iris cyst that resulted in severe visual impairment. Although successfully treated with surgery, the outcome would have been less complicated if the treatment was performed earlier in order to achieve a better visual prognosis.

Contributors: TDG: manuscript writing, literature review, patient management; WA: manuscript editing, literature review, and patient management. WA will act as guarantor. Both authors approved the final version of this manuscript. Funding: None; Competing interests: None stated. 


\section{References}

1. Shields CL, Shileds PW, Manalac J, Jumroendararasame C, Shields JA. Review of cystic and solid tumors of the iris. Oman Journal of Ophthalmology. 2013;6:159-164.

2. Gupta V, Rao A, Sinha A, Kumar N, Sihota R. Posttraumatic inclusion cysts of the iris: a longterm prospective case series. Acta Ophthalmologica Scandinavica. 2007;85:893-896.

3. Shields CL, Kancherla S, Patel J, Vijayvargiya P, Mayerling BS, Suriano M, et al. Clinical survey of 3680 iris tumors based on patient age at presentation. Ophthalmology. 2012;119:407-414.

4. Hadeer HA, Al-Towerki AE, Al-Rajhi A, Al-Awad A, Long-term follow-up and visual outcome after excision of a traumatic iris cyst by viscoelastic dissection. Int Ophthalmol. 2011;31:529-531.

5. Rishi P, Rishi E, Biswas J, Nandi K. Clinical and histopathological features of posttraumatic iris cyst. Indian J Ophthalmol. 2008;56:518-521.

6. Haller JA, Stark WJ, Azab A, Thomsen RW, Gottsch JD. Surgical management of anterior chamber epithelial cysts. Am J Ophthalmol. 2003;135:309-313.

7. Hong ES, Burden JH, Alward WLM. Intralesional ethanol for an unresectable epithelial inclusion cyst. JAMA Ophthalmol. 2013;131:262-263.

8. Rumelt V, Naumann GO. Block excision of congenital and infantile nonpigmented epithelial iris cysts. Report on eight infants. Ger J Ophthalmol. 1992;1:361-366.

9. Philip SS, John DR, Ninan F, John SS. Surgical management of post-traumatic iris cyst. The Open Ophthalmology Journal. 2015;9:164-166.

10. Venkateswaran N, Ching SST, Fischer W, Lee F, Yeaney G, Hindman HB. The diagnostic and therapeutic challenges of posttraumatic iris implantation cysts: illustrative case presentations and a review of the literature. Case Reports in Ophthalmological Medicine. 2015:1-11.

11. Rishi P, Rishi E, Biswas J, Nandi K. Clinical and histopathological features of posttraumatic iris cyst. Indian J Ophthalmol. 2008;56:518-521.

12. Charles JP, Vásquez LM, Lee R, Simpson ER, Ahmed IIK. Anterior segment optical coherence tomography and ultrasound biomicroscopy in the imaging of anterior segment tumors. Am J Ophthalmol. 2009;147:214-219.

13. Lockington D, Altaie R, Moore S, McGhee CNJ. Successful management of secondary iris cysts with viscoelastic-assisted endo-photocoagulation in letter. JAMA Ophthalmology. 2014;132:354-356.

14. Naumann GOH, Rummelt V. Block excision of cystic and diffuse epithelial ingrowth of the anterior chamber: report on 32 consecutive patients. Arch Ophthalmol. 1992;110:223-227.

15. Orlin SE, Rabner IM, Laibson PR, Shields CL, Brucker AJ. Epithelial down growth following the removal of iris inclusion cysts. Ophthalmic Surg. 1991;22:330-335. 